Forthcoming (Journal of Education Policy)

Variations on a middle class theme: English primary schools in socially advantaged contexts

Martin Thrupp and Ruth Lupton

Martin Thrupp is Professor of Education at the University of Waikato, New Zealand.

Ruth Lupton is Senior Research Fellow at the Centre for Analysis of Social

Exclusion, London School of Economics and Political Science. 


\section{Variations on a middle class theme: English primary schools in socially advantaged contexts}

Martin Thrupp and Ruth Lupton

Abstract: Multiple contexts interact to position any school on a spectrum from cumulatively advantaged to cumulatively disadvantaged. This article discusses a study of the contextual advantages and disadvantages experienced by primary schools in the South East of England, concentrating especially on schools in the least deprived $5 \%$ of schools nationally. The research highlights the central influence of advantaged socioeconomic contexts on day-to-day school processes and on the related perspectives and beliefs of headteachers as well as variations on this theme related to other external and internal contextual variables. It illustrates that England's most socially advantaged primary schools are likely to have much in common including a high level of parent involvement, a strong focus on student learning and progress, considerable ability to raise funds, very good reputations and only a handful of students with serious learning or behavioural problems. They also have in common middle class forms of transience and profiles of special needs. The article concludes that while contextual variations amongst socially advantaged schools do exist and are talked up by headteachers, they usually have an impact that can be managed. 
Numerous studies have illustrated that school processes and student achievement tend to reflect the socio-economic advantages or disadvantages of the communities and families they serve (Kozol 1991, 2005, Lupton 2004, 2005, Metz 1990, Mills and Gale 2009, Thomson 2002, Thrupp 1999). Not in any deterministic way of course: the agency of teachers and school leaders also has an impact, although it is a mistake to regard it as wholly independent of socio-economic context. Nor are socioeconomic influences the only local contextual factors that impact on schools. Other types of differences in pupil intake characteristics (ethnicity, turbulence, proportion of pupils from refugee families or with special needs) and other school and neighbourhood characteristics (urban/rural location, LEA policies, local school market, school history) can mediate the way socio-economic advantages or disadvantages impact on schools.

We are concerned with developing a nuanced understanding of all of the above. For the most part, teachers and school leaders experience socio-economic and other local contexts as 'givens' that constrain and enable their work and the ways in which they can exercise their agency. Multiple contexts interact to position any school on a spectrum from cumulatively advantaged to cumulatively disadvantaged. Better recognition of local contextual complexity could give rise to fairer national evaluation of school performance, fairer distribution of resources, and the provision of more appropriate advice and support to schools. All of these would enable better responses to the needs of school populations. Hence there is the need for research to consider school context in more detail, in order to provide a stronger underpinning

\footnotetext{
${ }^{1}$ Some intake characteristics and other local contexts may be able to be changed over an extended timeframe. But certainly in the short term they can rarely be changed.
} 
for contextualised policy and practice. We call this the 'contextualization agenda' for education research (Thrupp and Lupton 2006, Lupton and Thrupp 2007).

This is the first of two articles (see also Lupton and Thrupp, forthcoming) in which we explore the contextual advantages and disadvantages experienced by English primary schools. In this article we look at seven schools in the least deprived $5 \%$ nationally while the second article considers contextual variations amongst eight 'average' and somewhat more deprived schools (between the 50th and 75th percentiles nationally). The analysis illustrates the central influence of socioeconomic contexts on day to day school processes and on the related perspectives and beliefs of headteachers in each of the schools. It also illuminates variations between schools with similar socio-economic contexts arising from other external and internal contextual variables. For each school we have gathered quantitative data on a variety of intake and neighbourhood characteristics and we have also collected more information on external and internal contexts by way of interviews with each school's headteacher.

As well as providing factual detail on context, the interview data also usefully provides a sense of how each headteacher is understanding and responding to context. We regard such subjective 'readings' of context as an important form of agency to consider because they will create variation in the way context is perceived and acted upon. In this article on socially advantaged contexts we are particularly interested in a reading that stresses 'we have problems too'. This is where, rather than focussing on the relative contextual advantages of their setting, headteachers 
tacitly or overtly compare the difficulties they face with those of schools in more deprived settings even if they are hardly so serious in relative terms. We suggest this perception plays an important ideological role in supporting inequalities between schools as it helps to explain why staff in socially advantaged schools will often underestimate and downplay the extra demands on schools in more deprived areas and the resource implications of those extra demands.

\section{Research approach and methodology}

This article draws on a part of large mixed methods study ${ }^{3}$ which involved 44 primary and junior schools located in a town in the South East of England and its surrounding villages and rural areas. A key concern of this research, conducted from 2005-6, was to explore how variations in school contexts could be read off from existing statistical data, to support school management, performance assessment and accountability, and to this end we started with a statistical analysis of contextual variables. How we conceptualized and measured context for the 44 schools is discussed shortly. We were also interested to understand subjective readings of context, to illuminate nuances that cannot be picked up from statistical data, and to learn about contextual impacts on school processes. To do this we conducted wide-ranging interviews with the heads of the 44 schools, covering:

- Key challenges facing the school

- The nature of the area, and the school intake

- The head's overall view on the way in which the intake affects the work that the school does

\footnotetext{
3 'Primary School Composition and Student Progress', ESRC reference number RES-000-23-0784-A
} 
- Number of children on Free School Meals and the extent to which this reflects deprivation in the school

- The reputation of the school, the nature of the local market for schooling and the school's position in the market

- Trends in the school roll and reasons for any changes

- Numbers of pupils with special educational needs, and the kinds of needs

- Issues in working with parents, and the schools approach to this

- The level of pupil mobility, and the kind of mobility

- The school's approach to grouping and setting

- The school's approach to curriculum organisation, monitoring of pupil performance and preparation for standard tests

- Use of classroom assistants

- Issues in staff recruitment and retention and turnover

- The age/gender/experience profile of the staff

- Levels of staff morale

- The impact of workforce remodelling and the school's approach

- The fundraising activities of the school, the amount raised and what it is used for

- The extent and type of extra-curricular activities

- The existence and nature of any extended services, such as breakfast clubs

Many of these topics were canvassed because they had proved insightful in previous studies of school context (e.g., Thrupp 1999, Lupton 2004). It will be apparent that 
some encourage the description of school context, especially intake composition and the local educational market. Other areas allow for exploring how school processes may be affected by context, including looking at some specific processes that can be compared across schools, such as SATs preparation and the school's approach to grouping.

In this paper, we analyse interview data from the seven schools in our sample which were most advantaged on the statistical measures. It is important to recognize that the South East is generally a wealthy part of the UK and that the 44 schools in our sample are by no means nationally representative in terms of social deprivation. Only one school is deprived enough to be in the fifth $20^{\text {th }}$ (or $25 \%$ most deprived) of schools nationally (see Table 1 for detail on positioning of individual schools) ${ }^{4}$. On the other hand, 17 of the schools are in the twentieth $20^{\text {th }}$ (or $5 \%$ least deprived) of the national distribution. Given that our concern is with the detailed contextual differences between schools, this in itself is not a problem. Nevertheless readers should bear in mind that the national picture includes schools which are in more advantaged circumstances and, in particular, greatly more disadvantaged circumstances than those in our sample.

\section{Conceptualising and Measuring Context}

How should school context be measured? There is an extensive, largely quantitative, literature on 'neighbourhood effects', including such effects on children's cognitive

\footnotetext{
${ }^{4}$ The complete dataset includes both primary and secondary schools.
} 
development and educational outcomes (see for example Garner and Raudenbush 1991, Brooks-Gunn et al. 1993, McCulloch and Joshi 2000, Buck 2001, Atkinson and Kintrea 2004 and Bolster et al. 2007). Yet these studies provide little insight into how local context is influential. Galster (2010) provides the most recent and comprehensive summary of neighbourhood mechanisms, identifying 15 such mechanisms, grouped under four broad rubrics:

- Social interactive mechanisms (such as social networks and peer relations)

- Environment mechanisms (such as the influence of the physical environment)

- Geographical mechanisms (such as access to labour markets or amenities)

- Institutional mechanisms (such as the quality of local services).

He argues that studies of neighbourhood effects should explicitly try to explore these mechanisms, rather than simply seeking to identify associations between neighbourhood variables available in the data and individual outcomes. However, data limitations will always be a constraint.

A broader problem with applying the neighbourhood effects literature to school context is that the former is concerned with influences on individuals, the latter with influences on organisational process. There are potentially two sets of processes at work - neighbourhood effects on the individuals who make up the school, and neighbourhood effects that impact directly on the school itself. Thus, neighbourhood characteristics provide the environment in which educational habituses are formed (e.g., local labour market, access to services, social conditions, crime). They also impact directly on schools through, for example crime or environments for staff 
recruitment. Moreover, the neighbourhood dictates to a large extent ${ }^{5}$ the characteristics of the students in the school, that is, different features of school composition such as SES, ethnicity, SEN, student transience (Lupton 2006).

For this study, we attempted to capture context both in terms of school composition and in terms of social-interactive, environmental, geographical and institutional characteristics of the immediate neighbourhood. Drawing on a wide range of literature on relationships between background factors and educational success, we have measured school composition on three domains, as follows:

- educational need (including Special Educational Needs (SEN), English as an additional language (EAL), prior attainment and literate practices in the home $)^{6}$

- low income;

- family social capital (lone parent families and frequent residential moves.

Data on SEN, EAL and prior attainment was drawn principally from publicly available sources such as the national school performance tables and national pupil database. Low income is typically measured in England by the proportion of pupils eligible for Free School Meals (FSM). This measure fails to accurately capture the population of families in poverty, partly because families do not necessarily declare themselves eligible and partly because there is considerable movement in and out of eligibility.

\footnotetext{
${ }^{5}$ School markets are of course an important institutional factor affecting the neighbourhood/school relationship.

${ }^{6}$ SEN was based on a three-year average for 2003/4, 2004/5 and 2005/6, EAL and prior attainment on the characteristics of pupils in Y3 in 2004/5. Prior attainment is measured at age 5 (entry to primary school).
} 
FSM is only available to people on out-of-work benefits, primarily lone parents in areas of high employment such as the one in this study. For this reason, our measure of income is compiled from two measures used in a school-level deprivation index compiled by the Department for Children, School and Families using 2006 data, as part of a review of school funding. We add the proportion of families in out-of-work benefits and the proportion claiming working tax credit (and inwork benefit for people on low incomes). ${ }^{7}$

Data on household composition, family social capital and residential mobility were drawn from a questionnaire to Year 3 parents in all 44 schools. The purpose of the questionnaire was to gather more information on these and other socio-economic variables than is available in national datasets. ${ }^{8}$ It attracted a very high response rate (84\%, see Brown et al. 2005). However, within the smaller schools, overall numbers were still low, and thus the data was strongly influenced by the characteristics of individual families. For this reason, we have used the questionnaire data only for variables where no other suitable measure was available. We combined two residential mobility variables: the percentage of $\mathrm{Y} 3$ who had moved five or more times since birth and the mean number of moves in the year group. 'Literate practices' comprised three measures; the number of books in the home, whether parents read a newspaper regularly, and whether there was internet access in the home. The most robust data was collected in relation to literate practices, so we use

\footnotetext{
${ }^{7}$ The disadvantages of this dataset are that it was based on 2006 data (one year after the study) and that it does not measure benefits claims at the individual level but ascribes to each pupil in a school the benefit-claiming attributes of the small neighbourhood in which they live.

${ }^{8}$ This was designed to support quantitative analysis of relationships between school composition and pupil performance in the wider study, focusing on the cohort of children in Y3 in 2004/5. This is also the reason that some of the other variables in our dataset were only gathered for $\mathrm{Y} 3$ while others were collected on a school wide basis.
} 
that variable here. Gaining rounded measures of school context without primary data collection from parents remains a barrier to understanding the nuances of context.

The neighbourhood domains and indicators we chose were as follows, based on the electoral ward in which the school was located ${ }^{9}$ :

- Educational role models: percentage of 16 and 17 year olds (i.e. immediate role models) and percentage of $18-49 \mathrm{yr}$ olds (i.e. young adults up to parental age) with qualifications below level 2 (equivalent to five higher grade passes at GCSE, the English school leaving age);

- Employment prospects and role models: The percentage of people aged 1674 in routine or semi-routine jobs, and those who are unemployed or economically inactive (apart from people who are retired or students), and the rate of under- 18 conceptions, and

- Neighbourhood stability/social capital: The percentage of the population who moved into the area in the last year, the proportion of single parents and a measure of child density.

All these data were taken from the last available Census (2001) except teen conceptions data that are based on years 2001-2003 and taken from the Neighbourhood Statistics dataset. We are well aware that the data available is inadequate to capture completely the concepts were are trying to measure. For

\footnotetext{
${ }^{9}$ In this area electoral ward is the geography whose population most closely matches than needed to generate a two form entry for a primary school. While basing neighbourhood variables on the location of the school is in some respects problematic (because pupils travel to school), it is relatively robust in this context, where most children travel short distances to primary school and the local authority's admissions criteria are based on catchment areas. Our qualitative data enables us to identify cases of out-of-catchment admissions and their implications.
} 
example, we were able to find no physical or environmental measures, and our measures of social capital are at best proxies, since we have no data on individual social networks. Nevertheless, this is at the same time a more comprehensive attempt to measure local context than is typically employed in school performance monitoring, and one which is replicable and straightforward. Part of the purpose of this article is to examine what we can read off from such methods.

Table 1 provides the rankings of the 44 schools in relation to these measures. Table 2 characterizes the geographic location of the schools and provides actual figures. It will be apparent from these tables that most contextual variables follow from the level of deprivation found locally. At the more socially advantaged end of the table are schools which tend to be located in villages or have village-like suburban characteristics and which have high prior achievement, low numbers of SEN and EAL students, low turbulence and a low proportion of lone parent families. At the most deprived end of the table are typically urban estate schools with low prior achievement, relatively high levels of SEN pupils and in some cases EAL, high turbulence, a high proportion of lone parent families. Middling ranked schools in terms of deprivation often tend to be middling in terms of other contexts as well.

Table 1 about here

Table 2 about here

We have been experimenting with simple visual tools that allow comparison of the contextual features of schools occupying similar places on the spectrum of social 
deprivation/advantage. Figure 1 shows the seven extremely socially advantaged schools discussed in this article and as a group they can be contrasted with the eight most deprived schools in our study as shown in Figure 2. School composition variables are on the right hand side of these diagrams, neighbourhood variables on the left. Variables are standardized to their own mean across the 44 schools so that what is shown is on the scale is the number of standard deviations they are above or below the mean ${ }^{11}$. These diagrams illustrate how patterns of SES advantage or disadvantage are overwhelmingly followed by other kinds of advantages/disadvantages too. They do however indicate some contextual variation amongst schools of similar levels of deprivation. These 'variations on a theme', supported further by the qualitative accounts of heads are the main concern of this article.

Figure 1 about here

Figure 2 about here

Our discussion in this article moves from Juniper, the most socially advantaged school in our sample $\left(10.8 \%\right.$ on low incomes) to Elder, the $7^{\text {th }}$ most socially advantaged (14.57\% on low incomes). For reasons of space and ease of reading we have not tried to cover all the schools equally. Rather we have focussed most on Juniper and then covered the others only as much as necessary to illustrate their similarities and differences.

\footnotetext{
${ }^{11}$ The neighbourhood variables tend to have less variation than the school ones, partly because some of the schools fall in the same wards.
} 
Finally, in this discussion of context, we note that all of these factors and processes may be considered as 'external context'. We also want to consider what might be described as 'internal context'. Historical factors such as past leadership, past staffing stability, past resourcing and past reputation often weigh heavily on schools but they form contexts for which current staff can hardly be held responsible. There may also be some current internal factors that are more context than agency in the event that there is little the school could do about them. Examples would include significant staffing changes due to personal circumstances or schools being damaged by fire or flood. These cannot be readily captured by statistical measures but are revealed in the interview material.

\section{Juniper: an extremely socially advantaged school}

Juniper school was located in 'a very advantaged area as you might have guessed coming through the village, it's very attractive and a nice community to live in'. ${ }^{12}$ The head's assessment of deprivation backed up the data: 'it's a very very small minority who are not in a high income bracket'. Families were 'generally very stable, a lot of fathers are working in the IT industries or in London,' mothers were at home or working 'but it tends to be quite high powered a lot of it, its going back to the office as opposed to going back to the supermarket'. The head described how the wealthy professional parents at Juniper constituted a different demographic than many primary schools deal with:

\footnotetext{
${ }^{12}$ All quotes are from the head of the school being discussed.
} 
I think its to do with house prices and to do with people's jobs, many of our parents are more mature than I remember parents being. When I first started teaching a long time ago, parents would be in their 20 s with their children starting school, our parents are coming to their first child's parents meeting into their 40 s maybe even 50 for dads, so its quite interesting, it's a very different family profile than the one that used to be there 10 years ago.

Having such parents supporting the school was very helpful financially: the 'friends of the school' had raised 22,000 pounds over two years for a new music and drama room. At the same time the parents were articulate and confident and could be very demanding of the school:

...we're just about to update our Ofsted questionnaire which needs to be done and so in my wisdom I did a parents questionnaire, which is great in theory but in practice, the ones who are happy and contented don't send them in, and the ones who have the axe to grind do and that can be a little hurtful sometimes ... I think a lot of teachers have been a little stung by it, again it's a minority, tiny minority..

Parents at Juniper were ambitious for their children and sometimes overzealous about their academic progress: 
parents are concerned because they see their children as playing and they can't see the merit in it and actually these children are doing such amazing things, and this is where I was going back to, they're thinking, they're being independent they are using enquiry skills, they're using so many skills but I think these parents like them sitting in rows with pencils and filling in sums.

A culture of over-investment in children by working parents was also described:

I'm out working I want to support my child by making sure they do the swimming, and the judo, and the horse riding and the dancing and I think sometimes the children just need time out just to be imaginative and at home, ...some of them just seem to whiz around a huge number of [things]..

Despite this school's many advantages, the head identified some 'difficult' children:

...we've got one or two cohorts at the top of the school who have been very challenging indeed, all boys and for very different reasons, I mean some of them have got very particular needs, Aspergers or something like that which obviously has an impact... I should say the first three years they are entirely calm but at the top end we've got a group who have been difficult all the way through and I think they will continue to be, one tries 101 strategies.

Juniper was in a very dominant market position, being full to bursting with students and unable to take any students from outside catchment. The head described how 
national media coverage had strengthened its reputation:

A few years ago we had the dubious accolade as being classed as one of the top 20 schools in the country, which was a nonsense, I have to say it's a nonsense, it just happens that that one year we had $100 \%$ success in our SATS and...Barclays premiership banking looked at house prices and good school results and they put us together as being in the top $20 \ldots$. And it doesn't hold water actually, but the other side of it, it has a knock on effect because its gone in all the national papers, it then became a thing that you're a good school, or the reputation goes ahead of you, so we've very well sought after...When I first came to the school it seemed to be that not quite $50 \%$ but quite a large percentage of our children left at 7 for independent schools, that has completely gone away.

The head recognised that many parents would prefer smaller classes but could do little about it as the LEA was unwilling to allow extra classes when there was excess capacity in other nearby schools.

Juniper had more turbulence than some $($ rank $=23)$, but at this school turbulence was often a matter of parents moving internationally for work or lifestyle:

We've got children who've left us at different stages...and I think all of them have left because parents have gone abroad or they've moved elsewhere 
...there's nobody here who's gone to an independent school, one went to Australia, one went to New Zealand...

Only a few individual students were identified as having special needs:

We do have problems with family backgrounds. I mean we have two children who have support from [outside the school] and they have specific difficulties which are all related to self esteem and they're very angry children, in fact very disturbed children.

Turning now to the way Juniper responded to its intake, the head was able to identify quite specific learning concerns, 'moving children forward with writing', 'children's personal assessment of their work' and 'assessment for leaning' as key issues for the school. Discussion in these areas tended to assume children were capable, independent learners:

Its not just a case of 'we are following the curriculum, this is what we do, we have now done it so now we know it', its actually really looking at the assessments with the children, and the children being aware of where they are and what they don't understand and what they need to do and how they can address this and that's the area again which has to be really fine tuned.

As a school that was too small to have a class at each level, Juniper operated with mixed yeargroup classes and differentiated work offered for different groups of pupils 
within each class. This mixing across classes also enabled a culture where the school could push ahead students of high ability:

I've got four year 3 boys in the class of year 4 / 5 . They have done better than anybody else within that class, which just actually indicates how very able they are, because they have done better than their year 4 group.

It was also apparent that, dealing with a generally able, middle class intake, the school had considerable capacity to respond to any perceived learning issues. One indication of this capacity was that the head was able to spend some six weeks of the year out of the school acting as a consultant head to four other schools (This work also bought in extra funding to the school: about 10,000 pounds per year). On the other hand, whereas it is often assumed that high SES schools have fewer problems recruiting staff than those in deprived areas, Juniper often struggled to recruit because of the high cost of housing in the local area.

\section{Other extremely socially advantaged schools}

Mulberry was another village school of similar size to Juniper and followed many similar patterns. Parents were again heavily involved: 'they're cosseted by the parents too much', 'independence is a big thing because the parents will trudge in, carrying all their bags, that kind of thing' and were again willing and able to provide considerable financial support to the school: 'we had an auction of promises to raise money to develop the school grounds and on that one evening we raised $£ 9.5 \mathrm{k}$ '. As 
at Juniper, parents were also not slow to intervene in their child's schooling if they perceived any problem ('the letters start coming in, that kind of thing'), students were grouped within mixed year groups and it was often hard to recruit staff.

However there were also differences. Mulberry's most noteworthy differences from Juniper were considerable fluidity around enrolments and loss of students to private schools (Mulberry's frequent mobility rank $=1$, neighbourhood mobility $=4$ ). This school only had a small 'natural' catchment area in the village so it took in $40 \%$ of children from out of catchment with students coming from 15 different pre-schools overall. Like Juniper some moved on with transfers 'we've got parents that are directors, and executives of companies and they move out of the area to go elsewhere with their jobs' but a more serious issue was that from Years 3-5 many tended to go off to the private system:

as I say, the catchment area here is difficult, it's a small catchment area, so they all move. They go everywhere; you've got [names three private schools], lots of different places. There isn't one or two.

Such students were usually easily enough replaced by out of catchment students 'the Year Five at the moment, $80 \%$ of that class never started in reception year'. But this opened up the school to enrolling less advantaged and able students into its senior classes and it also created budget problems: 
There has been a trend in that, we tend to have the high achievers moving onto the private system and will get in. Because there's a place, people from [the nearby town] perhaps, less fortunate areas, and the children aren't as high achieving, so there has been a general pattern.

it all depends on January $17^{\text {th }}$ every year, your school budget is based on that one day, unfortunately for us last year we started off with 132 and we were down to 121 by January $17^{\text {th }}$. So we were funding the education of those children from our budget but not having anything in there. So our next year's budget is based on that very day, how many children were in school on that day...There's some small reimbursement once the budget comes through for changing numbers but it's nowhere near [enough].

One effect of this is that whereas the other socially advantaged schools in our sample were generally identifying some particular learning goal as their challenging issue of the moment, the Mulberry head said a key concern for that school was 'developing a PR strategy for the school [even though] we're over-subscribed in terms of pupil numbers'.

A second noteworthy difference between Juniper and Mulberry is that the latter had even fewer single parent families (rank=42). Unlike Juniper, Mulberry was a Church of England school and the head painted a picture of conservative family values pervading the school and the village: 
They have strong family values, I have to say, a strong sense of respect and behaviour. They're the type of children that don't like people misbehaving and don't like behaviour problems.

Spicebush was another Church of England school but like Mulberry its contextual indicators did not indicate any noteworthy differences from Juniper and in many ways this was borne out by the head's comments. Spicebush was described as 'reasonably privileged.... things like free school meals and indicators like that are not an issue. Also 'I think we only have one child who is not white Caucasian, not British' and 'our special needs issue is likely to become, very shortly, our more able people rather than the pupils that need additional support'. Nevertheless there were a few noteworthy differences. First, while parent support was 'fantastic' and the PTA typically raised 13000-15000 pounds per year, the head described a more broadminded relationship between parents and the school than at Juniper:

the premise is always that the school has got things right, initially....l'm not going to have somebody smashing my door down because their child says, "I had a bad day at school," or something like that. They would want to investigate why, probably, but they're certainly not going to take the child's side over a staff member for instance...l've recently come from another school, outside of this authority, where parents were highly aspirational and I would have lots of challenging from parents about certain things. No, I am very impressed at the trust that's reflected in me and my professionals...I guess I would explain it by saying that they know their capability, the capability of their 
children, and...and so are far more interested in the kind of broader curriculum rather than focussing in on why the SATs results are...I had a telephone conversation with a lady from just outside London who was talking about choosing another local school over mine, which... which is somewhat of a surprise. And it was down to the SATs results, and my parents, the parents of my existing children, would find that fairly abhorrent I think.

Second, Spicebush was located in an expensive village, but one a fair distance away from the town. This meant that it was more reliant on local students and was in fact a little undersubscribed in a way that might be unexpected for such a privileged school 'certainly the local estate agents are surprised if you tell them that there are spaces here'. Yet, third and despite this location, the head found it 'worryingly' easy to recruit teaching staff. On the other hand it was almost impossible to recruit low paid dinner ladies: 'they [people in the area] pay their gardener more.'

Spruce was another $C$ of $E$ village school with reasonably high mobility $(r a n k=10)$ and a higher proportion of single parent families than any of the schools so far (rank=16). Children here were described as 'articulate, well motivated children, who come from supportive families'. Some advantages of this kind of intake were noted:

because of the fact we've got in general well behaved children makes it an attractive place for other parents to come and say 'Yes l'd like my children to be here'. 
it's also 'Cool to be Clever' here. So some of the boys in year 6 who are quite bright sparks, they are looked up to. Whereas in some schools, they are teased mercilessly for being the boffs and whatever.

At Spruce there was mention of poorer families being a significant group:

Yes there is an affluent contingent at the school but there is also the other extreme where l've got farm labourers and farm workers who are in tied cottages.

[E]very term, the children go on a trip to do with a topic. Now not all parents can afford that, so [the PTA] do subsidise the trip as well.

This less affluent group was also likely to be the most mobile: 'a lot depends on the estate workers if they move to a different estate'. Like Juniper and all the schools so far Spruce was too small to have a class at each level, so it operated with mixed yeargroup classes and differentiated work offered for different groups of pupils within each class. Staffing at Spruce was settled - no teacher at this school had been there less than seven years and it was oversubscribed, about $3 / 4$ s of children coming from within its catchment and numerous enquiries from out of catchment:

it's because we're in a rural area, and there are so many more people moving from towns into the rural areas that I think that's what's happened. We've got a 
huge housing estate just the other side of [the town] and they're just on the edge of our catchment.

The head at Spruce described this schools enrolment situation as a big problem for the school:

I think the most challenging at the moment is the fact that we're oversubscribed and we're a small school and it's trying to serve the community and to keep everyone happy. We have endless phone calls and we have to say - we are full.

Cherry School had a more clearly rural location than any of the others so far: '[its] not a noticeable village. You go through it, you think, Is there a village there? There's a garage and bakery. Oh, it's gone'. It had a correspondingly small local catchment and like Mulberry was heavily dependent on out of catchment enrolments. While Cherry's contextual indicators were unexceptional, it also struggled with problems related to the affluence of intake already mentioned, including professional middle class turbulence, loss of students to private schools and 'demanding' parents:

You know, one year I was dreading seeing parents because it got to the stage "I'm sorry, we're going to move to the Isle of Wight" you know, established families. 'We've moved to Kingsbury and we can't get here from Kingsbury anymore."...Some to America, some to Cornwall, they've suddenly all gone. Normally it balances out, at the moment we're getting more out than in, but 
that's not always the case, and apparently that's typical of the school....we've cut a class before because we were right down to ninety, and then you go up to a hundred and forty. And it really is an issue for us, it's a big issue.

some go on till about year five because some of the independents take- some of the prep schools go from about nine, don't they, and they take them then. One or two for [private school] went in year five last year. And the intention had always been to send them to [private school], and that's when- they went slightly early, they went in the summer of year eight because they got sports scholarships and [private school] wanted them for their cricket in the summer.

And sometimes it's about saying to parents, you know, "Are you thinking you're putting too much pressure on this child?" ...And, yeah, it does affect you the nature of the children, because some parents are actually looking at your every move through a magnifying glass, and others send your children into school and let the school get on with it. That's it, that's school, school will do it. And what you want is a sort of fine balance really

Despite (or perhaps because of?) these struggles, the head of this school played down its contextual advantages:

There's a new estate, or a newish estate, over there, it's been there about three years, and we've never had a pupil from there.... They're very expensive, they were very expensive houses; they went from about four hundred thousand I 
think was the cheapest, to about seven hundred and fifty thousand. So that suggests independent education to me. Next year, I think, next September I think we're taking our first pupil from there

We haven't got any free school meals but we've got a heck of a lot of children on the special needs register.

Ash was a junior school of 240 students, about twice as large as any of the village schools discussed so far. Being a larger school allowed it to have classes at each year group with some ability grouping within these classes. The head of Ash argued separate infant and junior schools held back achievement gains in junior schools because of the effects of divided institutional loyalties:

And junior heads have been saying this for years and there is now respectable data which show that children appear to do better at the end of key stage 1 in an infant school rather than an all through primary because in an all through primary there may be a dialogue between the year 3 teacher and the year 2 teacher, saying 'are you absolutely sure [about the level of achievement]' and there can be a professional exchange of views without anybody feeling that one institution is trying to undermine or impose on the other...Some of the level 3s we get in from [infant school] may have been a level 3 on that day in May with the following wind and bright sunshine and all we can do is achieve a level 5 for them and if we achieve that then that is 2 levels, zero value added. 
Apart from being a larger school and a junior school, Ash again did not stand out much in terms of the contextual indicators but of course was far more complex once the quantitative account was considered. First $30-40 \%$ of its children were drawn from a military base where it enjoyed a better reputation than amongst the civilian population. The head explained this as follows:

It is possible though that the emphasis we give to settling the military children and the fact that these children come in and out and disturb all the routine of the stable, civilian reputation, that may be part of the issue. Because if you're part of the military you know that moves go with the territory...For the people who stay they may see during four years, three of their very best friends go and there isn't the compensation... its just 'oh they've gone and here are we'.

Second, the Head did not identify Ash as being a very advantaged school. Rather, in response to criticism from Ofsted that the school was not multicultural enough, he was keen to stress that the school did well with the various socio-economic elements of the community it served:

In civilian Ashtown there's pockets of really quite severe deprivation, 3 children and mum and dad living in a 2 bedroom flat. Er...there's a number of those, there's old farming Ashtown, there's social housing Ashtown , there's owner occupier detached 5 bedroom Georgian style Ashtown and there's town houses and semis.... we're pleased when we get children from the detached 5 bedroom, people living on Ashtown high street invariably access independent 
education, so there are those communities as well and all of them mix particularly well [in this school] but what this guy was saying was he didn't see enough evidence that in this very Anglo-centric white school that we had as educators opened our children's eyes enough to the realities of the world that they live in.

Similarly the military families were not as advantaged as the school's percentage of free school meals suggested:

mum is living in a military cottage miles away from any of her family back up, dad is away for up to 6 months of the year so effectively she is operating as a single parent.... So with military families what you might find characterises children in the civilian population, free school meals, there are lots of correlations, the one area where there isn't a correlation is in resources, and no minister in any government is going to put a military salary low enough to trigger free school meals, are they, obviously not. So we are forever being categorised with 'similar' schools that are [in a leafy town], which are as similar as chalk and cheese.

Third, Ash's school buildings did little to help the school:

This big unfriendly looking remote Victorian building... militates against what we actually want to do. That entrance hall is rather forbidding, the front door was driven in to the side of a chimney.... 
Fourth, a staffing problem had quite suddenly developed in the school, largely as a result of personal factors and promotions to other schools:

In the last two years a number of people's career paths all came to the same point simultaneously... So out of 8 permanent staff there could be er...well there are 3 gaps and a question mark.

Elder, the last school considered in this article, stood out on the context indicators as having a high number of EAL students (Rank=3). However this was still only $7 \%$ of intake and EAL students were hardly mentioned in the head's interview. The school was also the smallest of the seven schools (102 students) and had fairly high student mobility (rank=6).

At Elder the lack of independence of children was again noted: 'I think they have a lot done for them at home, I think Mum's run around after them'. On the other hand such privileged children could also suffer from a lack of parent attention:

[An] amazing number of them cannot use a knife and fork, so I don't know if they don't have meals together, I think a lot of I suppose the so-called better off childrens' fathers work in London, and aren't home until very late. So maybe they're having their dinner on their own, in front of the TV, I don't know... 
...you've got some children who come from good backgrounds who you'd think was economically good who don't really spend much time with their parents, they're with childminders or they're farmed around to every club going and don't have quality family time.

The head at Elder also wanted to stress the presence in the school of a significant minority of children from poorer families: 'so you have got two ends of the scale, you have got people living in million pound houses but you have also got people living on the council estates'. The latter were estimated at 30\%, although this is not supported by the context indicators, nor by some other comments:

Its just a very few children, its almost one family with their add ons, they seem to have cousins and other people who are affecting the rest of the school, even parents would like to see these families go...[They are] from the council estate down the road... Because of how they speak, how they look and really what they do outside the school. Because they're on bikes and they mess around in people's garages and hotwiring cars and doing some quite bad things, and they're known by the police, the police come here, they know who they are.

The children mixed well but parents didn't mix at all. For instance the parents association raised about 8000 pounds per year for the school, however:

The type of things they organise, a lot of the parents don't want to come to. They organise fashion shows and this type of thing and the people who live on 
the council estates don't want to come....I was trying to get them to do like a race night with fish and chips, something a bit more down to earth but they weren't very keen on that.

The school was in a village 'a bit chocolate boxey, so it appeals in that sense'. However because of the demographics of this wealthy little village, there were only two children from the village at the school. The others all came from surrounding areas and there had been problems keeping up enrolments in the past but a new private housing development within catchment meant there was now much more demand for the school. However the head described how student numbers were always touch and go for the school because of funding cut-off points used by the county:

[Keeping the roll up] is something that concerns the governors, they're always very concerned about it, and there's this magic number - 101, once you go below 101, when form 7 comes out in January, if you go below 101 it cuts quite a lot of your budget.

The size of school was described as a mixed blessing. On the one hand it was an advantage to have small class sizes: 'sometimes its like people who can't afford prep school, they see it as that a bit, because the classes are small' On the other it meant that the presence or absence of a particular child could heavily impact on SATs results: 
Last year $100 \%$ got science, $100 \%$ got English and something like $87 \%$ got maths, very high...It's perhaps maybe why this year lots of people came in, but this year it's not going to be so good.

It could also lead to turbulence when a critical mass of students, in this case the proportion of girls, broke down:

at the moment l've got year 4 , the year 4 has no girls in so its 9 boys, it did only have a few girls in like 4 or 5 but gradually they've gone, but when it got down to three those last three didn't want to be the last three in the year group so they left.

This was part of a loss of nearly $20 \%$ of students who had left the school and been replaced by others (hence the high mobility ranking). The turbulence was otherwise attributed to 'moving house and other people just didn't like a new head, a new regime and moved to other local schools'.

Being such a small school also made it more difficult to maintain distance from parents:

I've even had parents come, I had a lady come to see me just before the Easter holidays say 'I haven't got much money, where do you suggest I take my children out for a day.', Um and I'm thinking 'Not quite the Tourist Information' but it is like that. You are on their, it is their beck and call almost. 
Elder had little problem recruiting staff. The key issues for this school identified by the head were learning matters - writing and religious education (it was a Church of England school).

\section{Discussion and Conclusion}

Drawing on quantitative and qualitative data, our research confirms that there whilst there are patterns related to levels of deprivation which are predictable on the basis of the kinds of school and neighbourhood level indicators we have used for this study, some external and internal variation at the school site does need to be recognised if an accurate picture of contextual advantages and disadvantages is to emerge. There is also some variation in how contexts are understood and acted upon by staff. However we also believe that, among schools in the socially advantaged bracket that we have considered here, the level of contextual variation should not be overstated, and that in general, it is well within the agency of heads and their staff to run good schools given these local variations.

The seven schools discussed here had much in common in the way they manifested what might be expected on the basis of previous research findings about the middle class and education, the social geography of middle class school choice and the nature of schools with predominantly middle class intakes (e.g., Ball 2003, Butler with Robson 2003, Kozol 1991, Lareau 1989, Power et al. 2003, Thrupp 1999, Vincent and Ball 2006). All of the schools had a high level of parent involvement, a 
strong focus on student learning and progress, considerable ability to raise funds, very good reputations and only a handful of students with serious learning or behavioural problems. They also had in common middle class kinds of transience and middle class profiles of special needs that are different to those in average and high deprivation schools (Lupton and Thrupp forthcoming, Lupton, Thrupp and Brown forthcoming). These schools were among the most socially advantaged in England and in this sense they represent one extreme of the continuum of socioeconomic advantage and disadvantage.

At the same time there were differences between the schools. The most obviously exceptional school was Ash as this was a junior school rather than full primary school, was located in a more urban location and was much bigger than the others, allowing it to have a class at each year level rather than mixed year group classes as all the others did. This school also well illustrated some limitations of statistical data in picking up contextual differences. First the head's arguments about military salaries disguising working class backgrounds raises the problem that deprivation indicators are measures of socio-economic status, and especially income, rather than social class cultures. Ash also well illustrated the importance of internal contexts - this school's unhelpful buildings and unexpected staffing crisis - which measures of external contexts will not pick up.

The other schools also illustrated a range of differences. Mulberry and Cherry showed how some socially advantaged schools can suffer from uncertain market contexts because of their location and the attraction of private schooling to many 
middle class parents. In these two schools enrolment and retention of students displaced issues to do with student learning as the head's main 'issue of concern.' The schools also varied in the extent to which parents were aspirational in a demanding way and in their ability to recruit staff. All of these differences could be seen to be about agency: the way schools market themselves and relate to parents and prospective staff could undoubtedly have some impact on these differences. But clearly there were genuine contextual differences involved too. For instance Spicebush's parents would have been uncomfortable at the aspirational behaviour of parents at schools like Juniper where some parents 'liked them sitting in rows with pencils and filling in sums' and Cherry where some parents were 'looking at your every move through a magnifying glass'. It seems likely such differences reflected different middle class cultures or perhaps different fractions within the middle class. Elder was dealing with a particular issue around its size as it was only just bigger than the 'magic number' needed for greater funding.

Nevertheless it is important to recognize the limits of any exceptionality. As socially advantaged schools, none were having to deal with many students from urban estates, with low prior achievement or from lone parent families. Essentially the qualitative data backed up the contextual indicators that socially advantaged schools were advantaged contexts in numerous ways. However they were not uniformly advantaged and some of their advantages - being over subscribed, having 'demanding' parents, being mostly located in small, wealthy villages - were mixed blessings. 
The socially advantaged schools discussed here also illustrate a range of perceptions of context and responses to it. All the heads made reasonably realistic comments about their broadly advantaged situations (Ash claimed not to be as advantaged but probably for good reason) but within this context some of the heads overstated the problems they faced. For instance

Juniper: 'We do have problems with family backgrounds. I mean we have two children who have support from [outside the school]...'

Spruce: 'Yes there is an affluent contingent at the school but there is also the other extreme where l've got farm labourers and farm workers who are in tied cottages'.

Cherry: 'I mean, you look here, we haven't got any free school meals but we've got a heck of a lot of children on the special needs register'.

Elder: 'so you have got two ends of the scale, you have got people living in million pound houses but you have also got people living on the council estates'.

While it is unlikely that, if challenged, any of these headteachers would deny that other schools have greater difficulties, they were clearly keen to emphasise the problems they did have. This 'we have problems too' stance may point partly to heads being reluctant for their schools to be characterised as without some serious problems and the implication their jobs were too comfortable. However it may also be about schools being a bottomless pit of challenges/problems such that those faced by practitioners in socially advantaged schools tend to fill their horizons and 
use up their energies even if they are often not of the same order as those in socially disadvantaged school settings. When read alongside the interviews with heads of the more disadvantaged schools in our sample (see Lupton and Thrupp forthcoming), it also points to willingness and capacity by staff at socially advantaged schools to acknowledge and pick up problems that would be overlooked by more socially disadvantaged schools, for instance more focus on the problems of individual students (this might also reflect socially advantaged schools often being small village schools) or those who are 'average' but underachieving.

This perception is likely to play an important ideological role in supporting inequalities between schools because it means that staff in socially advantaged schools will often underestimate and downplay the extra demands on schools in more deprived areas and the resource implications of those extra demands. It helps to explain, for instance, why heads of socially advantaged schools are often unenthusiastic about funding being diverted to more deprived schools on equity grounds. It also underlines the importance of head teachers who act in advisory roles with government being drawn from schools in high deprivation settings as well as from more middle class settings where heads will often have more time to take up such positions.

While the issues raised here are generally contextual and therefore outside the control of heads, we think that in nearly all cases it is still within their agency to run good schools given these matters. In our view it is only Ash and Elder that presented contextual problems that require policy changes, in both cases to funding 
arrangements. For Ash the funding formula needs to reflect military deprivation, this is a local issue and as the head pointed out, there is better recognition in other parts of England:

the military life of [this area] is rich and has a profound influence and yet as far as the education service is concerned most of the time its as if we'd never learnt anything, we've never seen somebody in military uniform. In [another area] for categorisation and funding purposes they've come to an agreement that for every 2.5 service children you can score 1 free school meal and I think the message is being taken across to [other areas].

At Elder, the problem was a substantial funding step which created much uncertainty for a school which hovered around the 'magic number'. A more gradual funding scale might remove this uncertainty and would be worth exploring. However the other problems lie within what we could expect of any senior manager because the highly socially advantaged school environment means they are not so serious. For instance competition from private schools is a problem for some of the schools, but most can recruit anyway because they are 'popular' schools with high positional value.

The value of illustrating contextual variations amongst such socially advantaged schools as discussed here is to demonstrate that while heads talk them up, they usually have an impact which can be managed. A very different set of circumstances will be illustrated when we look at more deprived settings (Lupton and Thrupp forthcoming). In socially deprived schools contextual variation has a massive impact. 
While policy approaches in such settings come to rely on extraordinary people, in practice the agency of heads and teachers generally constitutes an inadequate response. The achievements of staff are often substantial, but the challenges go beyond what can reasonably be expected without substantial extra resources and reorganisation.

\section{References}

Atkinson, R. and Kintrea, K., 2004. "Opportunities and Despair, it's All in There": Experiences and Explanations of Area Effects and Life Chances', Sociology, 38 (3) $437-455$.

Ball, S.J. (2003) Class Strategies and the Educational Market: the middle classes and social advantage. London: Routledgefalmer.

Bolster, A. et al., 2007. Neighbourhoods, Households and Income Dynamics: a Semi-parametric Investigation of Neighbourhood Effects. Journal of Economic Geography, 7 (1),1-38.

Brooks-Gunn, J., Duncan, G., Klebanov, P, and Sealand, N., (1993) ‘Do

Neighborhoods Influence Child and Adolescent Development? American Journal of Sociology, 99, (2), 353-395.

Butler, T. with Robson, G. (2003) London Calling; The middle classes and the remaking of Inner London. Oxford: Berg. 
Buck, N. (2001) 'Identifying Neighbourhood Effects on Social Exclusion' Urban Studies 38, 2251- 2275

Brown, C., Thrupp, M., Kounali, D., Lauder, H., Robinson, T., Goldstein, H., Guy. P. and Hill, N. (2005). Pulling out all the stops: Achieving a 'miraculous' response rate. Paper presented to the 2005 BERA conference, 14-16 September, University of Glamorgan, Wales.

Galster G. (2010) The Mechanism(s) of Neighborhood Effects: Theory, Evidence, and Policy Implications. Presented at ESRC Seminar: "Neighbourhood Effects: Theory \& Evidence" St. Andrews University, Scotland, UK 4-5 February, 2010

Garner, C. and Raudenbush (1991) 'Neighborhood Effects on Educational Attainment: A Multi-Level Analysis,' Sociology of Education, 64 (4), 251-262

Kozol, J. (1991). Savage inequalities. New York: Crown Publishing.

Kozol, J. (2005). The shame of the nation. New York: Crown Publishing.

Lareau, A. (1989) Home Advantage. Philadelphia: Falmer Press.

Lupton, R. (2004). Schools in disadvantaged areas: Recognising context and raising performance (CASE paper 76) London: Centre for Analysis of Social Exclusion London School of Economics and Political Science.

Lupton, R. (2005). Social justice and school improvement: Improving the quality of schooling in the poorest neighbourhoods. British Educational Research Journal 31, no. 5: 589-604 
Lupton, R. (2006) How does Place Affect Education, in Delorenzi,S. (ed) Going Places: Neighbourhood, Ethnicity and Social Mobility. London: Institute of Public Policy Research

Lupton, R. and Thrupp, M. (2007). Taking local contexts more seriously: the challenge for educational research, policy and practice. In Social inequality in education: International perspectives on theory and policy, ed. R.Teese., M. Duru-Bellat, and S. Lamb. Dordrecht: Springer.

Lupton, R. \& Thrupp, M. (forthcoming) Variations on a theme: English primary schools in average and high deprivation contexts.

Lupton, R., Thrupp, M. and Brown, C. (forthcoming). Special educational needs: a contextualised perspective.

McCulloch, A. and Joshi, H. (2000) Neighbourhood and Family Influences on the Cognitive Ability Children in the British National Child Development Study, ISER Working Paper 2000-24, Colchester: Institute for Social and Economic Research, University of Essex

Metz, M. H. (1990). How social class differences shape teachers work. In The contexts of teaching in secondary schools, ed. M. W. McLaughlin, J. E. Talbert and N. Bascia, 40-107. New York: Teachers College Press.

Mills, C. and Gale, T. (2009). Schooling in disadvantaged communities: Playing the game from the back of the field. New York: Springer. 
Power. S., Edwards , T., Whitty, G., and Wigfall, V. (2003) Education and the Middle Class. Maidenhead: Open University Press

Thrupp, M. (1999). Schools making a difference: Let's be realistic! School mix, school effectiveness and the social limits of reform. Buckingham: Open University Press.

Thrupp, M. and Lupton, R (2006) Taking school contexts more seriously: the social justice challenge. British Journal of Educational Studies 53, no. 3: 308-328.

Thomson, P. (2002). Schooling the rust-belt kids: Making the difference in changing times. Stoke-on-Trent: Trentham Books.

Vincent, C and Ball, S. (2006) Childcare, Choice and Class Practices. London: Routledge. 
School name

Beech

Cypress

Cedar

Aspen

Palmtree

Willow

Redwood

Fir

Lilac

Maple

Poplar

Hazel

Birch

Sycamore

Yellowood

Alder

Hollybush

Elm

Hawthorn

Ivy

Pinetree

Walnut

Laburnam

Rowan
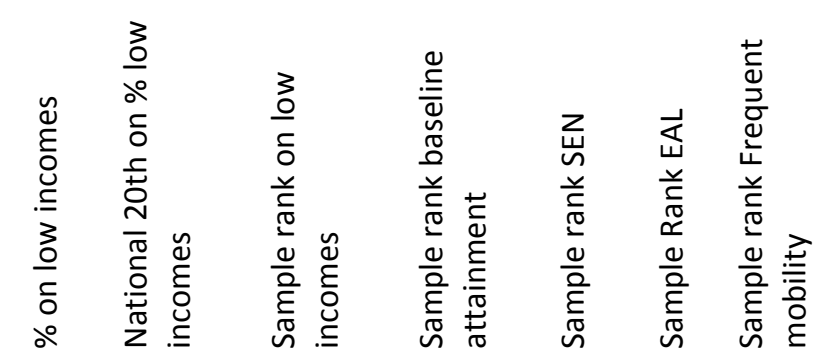

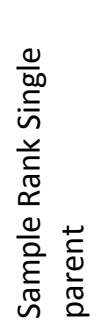

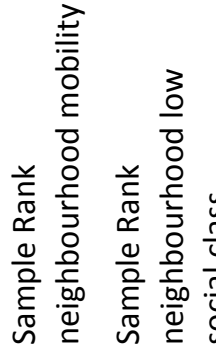

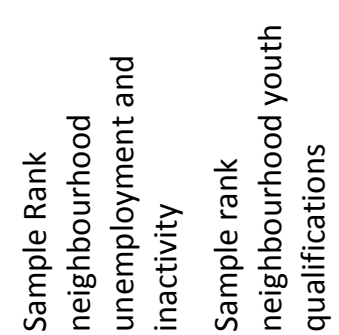

$52.74 \%$

$48.73 \%$

$47.34 \%$

$47.32 \%$

$46.97 \%$

$42.91 \%$

$37.73 \%$

$37.43 \%$

$36.95 \%$

$31.94 \%$

$30.07 \%$

$29.51 \%$

$29.38 \%$

$29.29 \%$

$28.61 \%$

$24.57 \%$

$23.51 \%$

$21.28 \%$

$20.17 \%$

$20.16 \%$

$19.60 \%$

$19.40 \%$

$19.07 \%$

$18.00 \%$
37

85

19
37

18

21

6

10

26

37

16

31

33

36

27

12

37

13

30

5

21

21
4
37

2 


\begin{tabular}{|c|c|c|c|c|c|c|c|c|c|c|c|c|}
\hline Oak & $17.65 \%$ & 19 & 25 & 35 & 24 & 23 & 15 & 11 & 34 & 32 & 20 & 29 \\
\hline Rubbertree & $17.63 \%$ & 19 & 26 & 41 & 35 & 23 & 20 & 28 & 32 & 18 & 31 & 15 \\
\hline Larch & $17.50 \%$ & 19 & 27 & 16 & 42 & 22 & 28 & 24 & 44 & 26 & 44 & 37 \\
\hline Olivetree & $16.78 \%$ & 20 & 28 & 17 & 25 & 23 & 35 & 19 & 11 & 23 & 38 & 20 \\
\hline Magnolia & $15.85 \%$ & 20 & 29 & 38 & 20 & 23 & 29 & 39 & 15 & 20 & 23 & 22 \\
\hline Myrtle & $15.78 \%$ & 20 & 30 & 30 & 27 & 12 & 17 & 31 & 2 & 42 & 40 & 22 \\
\hline Dogwood & $15.63 \%$ & 20 & 31 & 13 & 29 & 10 & 25 & 25 & 5 & 40 & 42 & 31 \\
\hline Crabapple & $15.38 \%$ & 20 & 32 & 10 & 19 & 23 & 14 & 36 & 39 & 25 & 10 & 14 \\
\hline Chestnut & $15.32 \%$ & 20 & 33 & 42 & 38 & 17 & 24 & 40 & 28 & 35 & 32 & 38 \\
\hline Eucalyptus & $14.91 \%$ & 20 & 34 & 31 & 40 & 21 & 34 & 34 & 33 & 38 & 34 & 39 \\
\hline Plumtree & $14.77 \%$ & 20 & 35 & 11 & 21 & 20 & 32 & 29 & 42 & 33 & 16 & 33 \\
\hline Gumtree & $14.64 \%$ & 20 & 36 & 44 & 26 & 23 & 37 & 8 & 28 & 35 & 11 & 42 \\
\hline Ferntree & $14.60 \%$ & 20 & 37 & 39 & 44 & 23 & 3 & 36 & 25 & 27 & 14 & 33 \\
\hline Elder & $14.57 \%$ & 20 & 38 & 21 & 18 & 3 & 6 & 26 & 19 & 30 & 14 & 33 \\
\hline Ash & $14.34 \%$ & 20 & 39 & 27 & 12 & 19 & 9 & 35 & 19 & 30 & 23 & 22 \\
\hline Cherry & $13.51 \%$ & 20 & 40 & 28 & 14 & 23 & 37 & 43 & 15 & 20 & 11 & 42 \\
\hline Spruce & $13.45 \%$ & 20 & 41 & 19 & 23 & 23 & 10 & 16 & 25 & 27 & 28 & 30 \\
\hline Spicebush & $11.22 \%$ & 20 & 42 & 43 & 36 & 23 & 37 & 38 & 18 & 37 & 37 & 41 \\
\hline Mulberry & $10.90 \%$ & 20 & 43 & 36 & 39 & 23 & 1 & 42 & 4 & 39 & 34 & 39 \\
\hline Juniper & $10.81 \%$ & 20 & 44 & 29 & 28 & 23 & 23 & 22 & 42 & 33 & 16 & 33 \\
\hline
\end{tabular}

Table 1 National positioning of the 44 sample schools in relation to social deprivation and their sample rankings on social deprivation and other context indicators 


$\begin{array}{ll}\text { School name } & \text { Urban/Rural } \\ \text { Cherry } & \text { Hamlet and Isolated Dwelling } \\ \text { Ivy } & \text { Urban }>10 \mathrm{k} \\ \text { Hawthorn } & \text { Village } \\ \text { Hollybush } & \text { Urban }>10 \mathrm{k} \\ \text { Birch } & \text { Urban }>10 \mathrm{k} \\ \text { Alder } & \text { Urban }>10 \mathrm{k} \\ \text { Cypress } & \text { Urban }>10 \mathrm{k} \\ \text { Beech } & \text { Urban }>10 \mathrm{k} \\ \text { Rowan } & \text { Hamlet and Isolated Dwelling } \\ \text { Elder } & \text { hamlet and Isolated Dwelling } \\ \text { Maple } & \text { Village } \\ \text { Poplar } & \text { Urban }>10 \mathrm{k} \\ \text { Dogwood } & \text { Urban }>10 \mathrm{k} \\ \text { Elm } & \text { Urban }>10 \mathrm{k} \\ \text { Oak } & \text { Town and Fringe } \\ \text { Pinetree } & \text { Urban }>10 \mathrm{k} \\ \text { Larch } & \text { Urban }>10 \mathrm{k} \\ \text { Lilac } & \text { Urban }>10 \mathrm{k} \\ \text { Magnolia } & \text { Town and Fringe } \\ \text { Mulberry } & \text { Village } \\ \text { Palmtree } & \text { Urban }>10 \mathrm{k} \\ \text { Ash } & \text { Town and Fringe } \\ \text { Willow } & \text { Urban }>10 \mathrm{k}\end{array}$

\begin{tabular}{|c|c|c|c|c|c|c|c|c|c|}
\hline 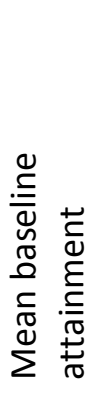 & $\begin{array}{l}\% \\
\text { SEN }\end{array}$ & $\begin{array}{l}\% \\
\text { EAL }\end{array}$ & 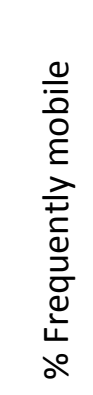 & $\begin{array}{l}\frac{1}{2} \\
\frac{0}{0} \\
\frac{0}{0} \\
\frac{0}{0} \\
\frac{0}{00} \\
\frac{5}{n} \\
\text { do }\end{array}$ & 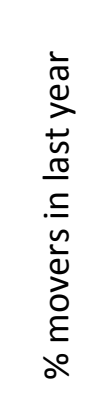 & 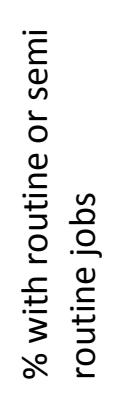 & 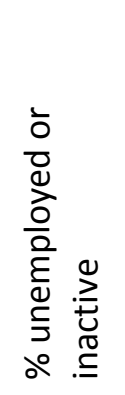 & 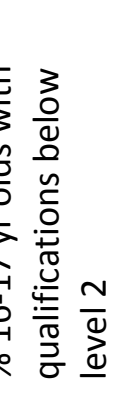 & 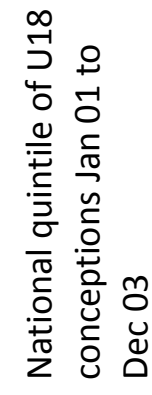 \\
\hline 2.73 & 20.7 & $0 \%$ & $0 \%$ & $6 \%$ & 0.14 & 0.17 & 0.13 & 0.49 & 5 \\
\hline 2.47 & 20.8 & $0 \%$ & $9 \%$ & $13 \%$ & 0.15 & 0.16 & 0.10 & 0.49 & 2 \\
\hline 2.95 & 9.2 & $0 \%$ & $0 \%$ & $0 \%$ & 0.12 & 0.19 & 0.15 & 0.50 & 3 \\
\hline 2.53 & 33.7 & $0 \%$ & $4 \%$ & $20 \%$ & 0.12 & 0.20 & 0.12 & 0.54 & 3 \\
\hline 2.45 & 23.2 & $3 \%$ & $8 \%$ & $19 \%$ & 0.11 & 0.29 & 0.14 & 0.53 & 1 \\
\hline 2.42 & 14.5 & $4 \%$ & $2 \%$ & $15 \%$ & 0.14 & 0.24 & 0.10 & 0.49 & 2 \\
\hline 1.89 & 27.8 & $3 \%$ & $0 \%$ & $37 \%$ & 0.15 & 0.36 & 0.18 & 0.65 & 2 \\
\hline 2.41 & 32.2 & $0 \%$ & $0 \%$ & $46 \%$ & 0.15 & 0.36 & 0.19 & 0.62 & 2 \\
\hline 2.39 & 14.3 & $0 \%$ & $15 \%$ & $38 \%$ & 0.13 & 0.14 & 0.15 & 0.28 & 5 \\
\hline 2.47 & 19.5 & $7 \%$ & $13 \%$ & $13 \%$ & 0.14 & 0.14 & 0.14 & 0.43 & 4 \\
\hline 3.05 & 32.0 & $0 \%$ & $12 \%$ & $12 \%$ & 0.12 & 0.19 & 0.15 & 0.50 & 3 \\
\hline 2.90 & 10.4 & $0 \%$ & $4 \%$ & $20 \%$ & 0.22 & 0.17 & 0.13 & 0.48 & 1 \\
\hline 2.40 & 15.0 & $3 \%$ & $4 \%$ & $13 \%$ & 0.19 & 0.11 & 0.10 & 0.43 & 4 \\
\hline 2.66 & 20.7 & $3 \%$ & $11 \%$ & $15 \%$ & 0.19 & 0.11 & 0.10 & 0.43 & 4 \\
\hline 2.98 & 17.6 & $0 \%$ & $8 \%$ & $22 \%$ & 0.13 & 0.14 & 0.14 & 0.46 & 5 \\
\hline 2.25 & 14.5 & $5 \%$ & $4 \%$ & $16 \%$ & 0.20 & 0.11 & 0.10 & 0.49 & 3 \\
\hline 2.42 & 8.9 & $1 \%$ & $4 \%$ & $14 \%$ & 0.09 & 0.15 & 0.08 & 0.42 & 4 \\
\hline 2.29 & 19.9 & $7 \%$ & $13 \%$ & $16 \%$ & 0.17 & 0.24 & 0.13 & 0.54 & 1 \\
\hline 3.13 & 18.9 & $0 \%$ & $4 \%$ & $7 \%$ & 0.14 & 0.17 & 0.13 & 0.49 & 5 \\
\hline 3.00 & 10.3 & $0 \%$ & $20 \%$ & $7 \%$ & 0.20 & 0.11 & 0.10 & 0.37 & 5 \\
\hline 2.03 & 22.2 & $4 \%$ & $7 \%$ & $32 \%$ & 0.15 & 0.36 & 0.19 & 0.62 & 2 \\
\hline 2.68 & 22.1 & $2 \%$ & $13 \%$ & $9 \%$ & 0.14 & 0.14 & 0.14 & 0.43 & 4 \\
\hline 2.08 & 41.9 & $0 \%$ & $0 \%$ & $24 \%$ & 0.13 & 0.33 & 0.14 & 0.56 & 3 \\
\hline
\end{tabular}




\begin{tabular}{|c|c|c|c|c|c|c|c|c|c|c|}
\hline Juniper & Village & 2.84 & 15.5 & $0 \%$ & $5 \%$ & $15 \%$ & 0.10 & 0.14 & 0.11 & 0.40 \\
\hline Plumtree & Town and Fringe & 2.37 & 18.4 & $1 \%$ & $3 \%$ & $12 \%$ & 0.10 & 0.14 & 0.11 & 0.40 \\
\hline Redwood & Urban > 10k & 2.30 & 33.0 & $10 \%$ & $7 \%$ & $21 \%$ & 0.16 & 0.30 & 0.16 & 0.60 \\
\hline Rubbertree & Hamlet and Isolated Dwelling & 3.20 & 13.2 & $0 \%$ & $6 \%$ & $13 \%$ & 0.13 & 0.19 & 0.12 & 0.51 \\
\hline Cedar & Urban > 10k & 2.15 & 26.4 & $3 \%$ & $13 \%$ & $32 \%$ & 0.14 & 0.33 & 0.16 & 0.58 \\
\hline Spruce & Village & 2.46 & 17.7 & $0 \%$ & $12 \%$ & $18 \%$ & 0.13 & 0.14 & 0.15 & 0.28 \\
\hline Sycamore & Urban > 10k & 2.61 & 20.4 & $6 \%$ & $3 \%$ & $24 \%$ & 0.14 & 0.21 & 0.11 & 0.49 \\
\hline Walnut & Village & 3.17 & 7.1 & $0 \%$ & $14 \%$ & $7 \%$ & 0.13 & 0.11 & 0.12 & 0.48 \\
\hline Aspen & Urban > 10k & 2.03 & 52.3 & $4 \%$ & $18 \%$ & $43 \%$ & 0.16 & 0.30 & 0.16 & 0.60 \\
\hline Hazel & Urban > 10k & 2.87 & 18.3 & $4 \%$ & $0 \%$ & $17 \%$ & 0.14 & 0.33 & 0.16 & 0.58 \\
\hline Yellowood & Urban > 10k & 2.60 & 14.8 & $3 \%$ & $3 \%$ & $10 \%$ & 0.13 & 0.33 & 0.14 & 0.56 \\
\hline Myrtle & Urban > 10k & 2.85 & 15.6 & $3 \%$ & $7 \%$ & $11 \%$ & 0.20 & 0.11 & 0.10 & 0.49 \\
\hline Gumtree & Hamlet and Isolated Dwelling & 3.75 & 16.4 & $0 \%$ & $0 \%$ & $25 \%$ & 0.13 & 0.12 & 0.14 & 0.43 \\
\hline Crabapple & Village & 2.36 & 19.3 & $0 \%$ & $8 \%$ & $8 \%$ & 0.12 & 0.16 & 0.15 & 0.52 \\
\hline Eucalyptus & Urban > 10k & 2.87 & 9.5 & $1 \%$ & $3 \%$ & $9 \%$ & 0.13 & 0.11 & 0.11 & 0.40 \\
\hline Olivetree & Urban > 10k & 2.43 & 17.5 & $0 \%$ & $2 \%$ & $16 \%$ & 0.15 & 0.16 & 0.10 & 0.49 \\
\hline Ferntree & Town and Fringe & 3.16 & 2.2 & $0 \%$ & $17 \%$ & $8 \%$ & 0.13 & 0.14 & 0.15 & 0.28 \\
\hline Laburnam & Town and Fringe & 2.63 & 14.6 & $0 \%$ & $5 \%$ & $10 \%$ & 0.14 & 0.19 & 0.13 & 0.48 \\
\hline Spicebush & Village & 3.70 & 11.4 & $0 \%$ & $0 \%$ & $8 \%$ & 0.14 & 0.12 & 0.12 & 0.43 \\
\hline Fir & Urban > 10k & 2.17 & 27.0 & $2 \%$ & $5 \%$ & $31 \%$ & 0.11 & 0.29 & 0.14 & 0.53 \\
\hline Chestnut & Village & 3.24 & 10.4 & $2 \%$ & $5 \%$ & $7 \%$ & 0.13 & 0.12 & 0.14 & 0.43 \\
\hline
\end{tabular}

Table 2: Type of locality and context indictors for the 44 schools 


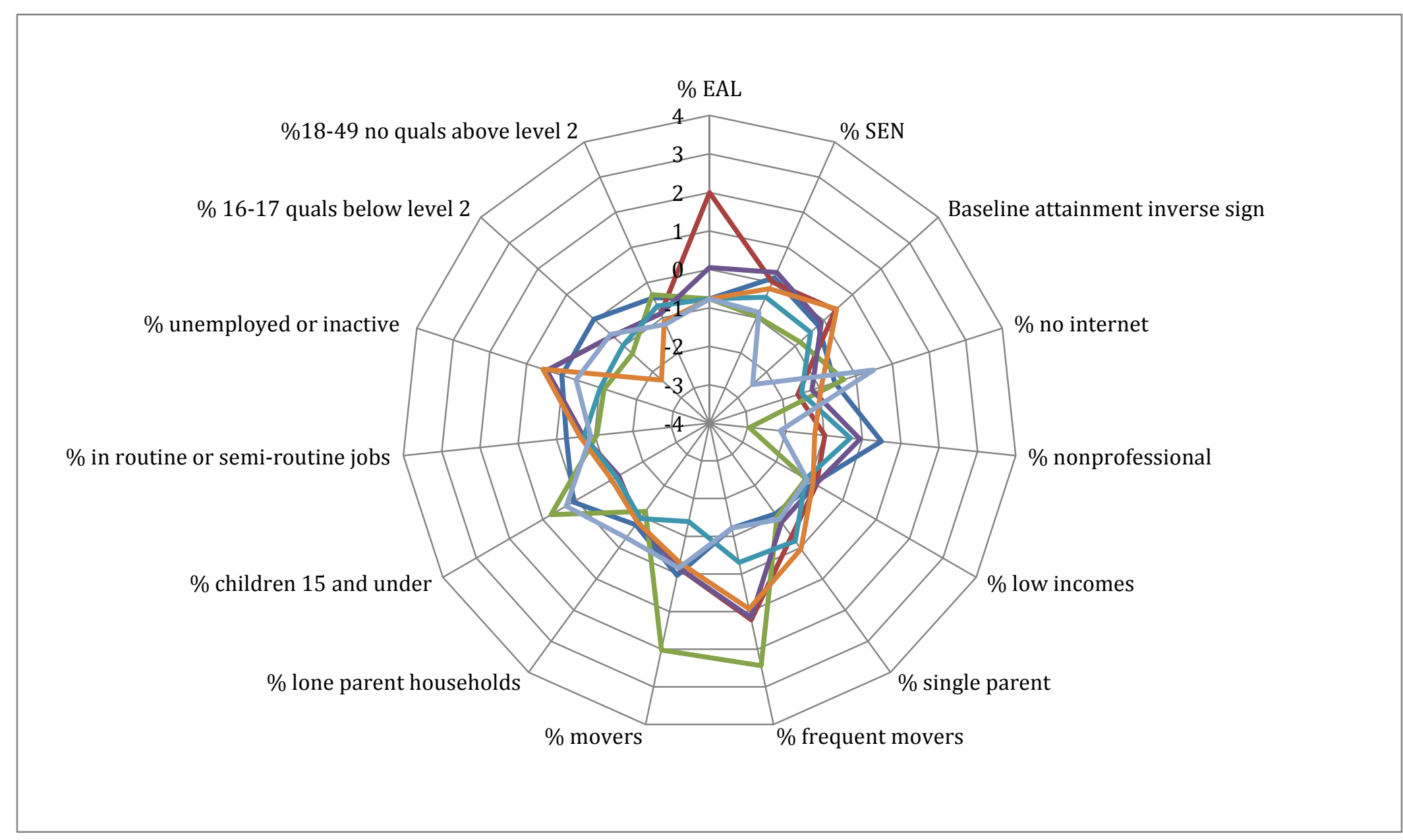

Figure 1 The most socially advantaged schools in our sample ${ }^{13}$

${ }^{13}$ A version of this diagram which is colour-coded to identify particular schools is available from the authors 


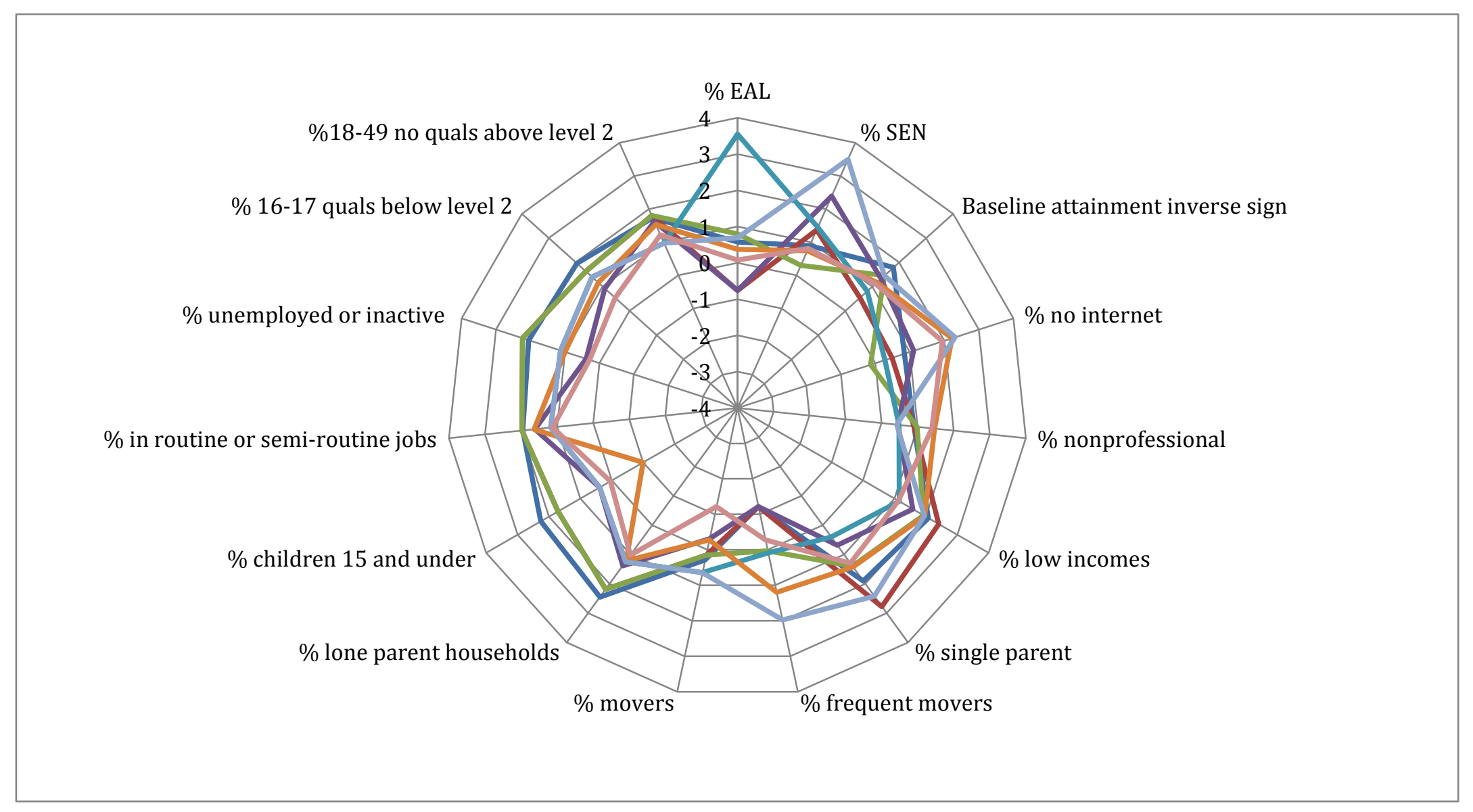

Figure 2 The highest deprivation schools in our sample ${ }^{14}$

${ }^{14}$ A version of this diagram which is colour-coded to identify particular schools is available from the authors 